\title{
We are the change we want to see
}

\author{
Carl Grant* \\ Associate Dean, Knowledge Services \& Chief Technology Officer, University of Oklahoma Libraries, \\ 401 W. Brooks Street, N.W., Room 212, Norman, OK 73019, USA
}

\begin{abstract}
Libraries are seeking, in fact driving, change on their campuses. The oppressive costs of information are creating the need to unleash new value from information silos and thus are driving the change. This paper identifies the barriers to that change and how, in some cases, they're being overcome. Some of the solutions are technology and some are innovative new spaces that facilitate collaboration and innovation. Examples are identified. In addition, the key roles of connections and cognitive cities are briefly explored as examples of other directions technology is leading. When combined with spaces, the result is entirely new levels of innovation in academic libraries.
\end{abstract}

Keywords: ARL expenditure trends, higher education state funding, information value, curse of knowledge, open access, collaborative learning commons, digital scholarship, carpentries, research bazaars, 3D printing, virtual reality, microcontrollers, learning lab, writing center, tutoring center, visualization, interactive learning communities, research output management system, innovation engines, exaptation

\section{Introduction}

"Complaining about a problem without posing a solution is called whining."

President Theodore Roosevelt

"Change will not come if we wait for some other person, some other time. We are the ones we have been waiting for. We are the change we seek."

President Barak Obama.

Many public higher education institutions are, in today's (2018) environment, facing massive changes in state funding. For instance, in my home state, looking at FY12-FY17, Oklahoma has taken the lead in making these kinds of cuts and has currently cut funding to higher education by $18 \%$. Meanwhile, the expenditure trends for research libraries show that between 1986 and 2015, while the Consumer Price Index has increased by $118 \%$, the cost for library materials has increased by $352 \%$ and the cost of serials expenditures has increased by $521 \%$.Libraries very much feel like they are caught in a crippling squeeze.

*E-mail: carl.grant@ou.edu.

0167-5265/18/\$35.00 @ 2018 - IOS Press and the authors.

This article is published online with Open Access and distributed under the terms of the Creative Commons Attribution Non-Commercial License (CC BY-NC 4.0). 
For instance, at the University of Oklahoma Libraries in 2010 database expenditures (by format) were $19 \%$, books $24 \%$, and serials $57 \%$. By 2017 , in response to these trends, the allocation had changed to databases being $23 \%$ of our expenditures (by format), books $10 \%$, and serials $67 \%$. Clearly this is not a sustainable trend for libraries. The day is visible when in order to sustain serials subscription costs a research library will not be able to purchase any books. Something must change.

And change is occurring all around us, with implications that must be observed and respected, certainly in the publishing/content industry and by libraries. At a high level, consider what Thomas Friedman pointed out in his book Thank You for Being Late, where he states that around the year 2007 the following things were introduced:

- iPhone

- Hadoop (big data)

- GitHub

- Facebook (Sept 2006)

- Twitter

- Google bought YouTube (2006)

- Android launched

- Kindle released

- IBM released Watson

- Intel released high-k-metal gate microchips

Friedman summarizes that list by calling it "One of the greatest leaps in history [1]." Of course, few would disagree with that assessment. We now live in an age where, as Kevin Kelly points out in his recent book The Inevitable "every 12 months we produce 8 million new songs, 2 million new books, 16,000 new films, 30 billion blog posts, 182 billion tweets, and 400,000 new products [2]." This is an information explosion of unprecedented scale. Bernard Marr summed it up this way in a recent Forbes article: "By 2020, about $1.7 \mathrm{Mb}$ of new information will be created every second for every human being on the planet." and "Our accumulated universe of data will grow to 44 trillion Gb [3]."

Yes, there is an inherent challenge with this information explosion. That challenge is the capacity of the human mind to deal with it. While the average laptop computer today has a $500 \mathrm{~Gb}$ disk, Sloman/Fernbach, in The Knowledge Illusion, point out that the average human being has, in their mind at any one point, "about $1 \mathrm{~Gb}$ of information [4]". (They pose some interesting tests which can be readily used to prove this to yourself). What does this mean for humans? "The sum of knowledge has far outstripped any single individual's capacity to learn," per Teller, the CEO of Google X.

The grand result? Information has now reached a "commodity" status. What's frustrating about this is the reality that additional value held by information is being locked up because information is "contained" in:

- Database Silos

- Document containers (PDF, Docx, AZW, etc.)

- Behind paywalls

- Legal contracts/restrictions

- Clumsy/difficult access 
Let me repeat, this means the additional value of information is being held back. It needs to be unleashed. For librarians, for vendors, for people. Yet we see business leaders not understanding that they're locking up the very value they seek. Recently, in The Guardian, there was an article where the CEO of Hachette Livre, Arnaud Nourry, reportedly said: "Ebooks are stupid." and "This lack of creativity is partly publishers' lack of digital know-how," according to Nourry. "We, as publishers, have not done a great job going digital. We've tried. We've tried enhanced or enriched ebooks - didn't work - but I reached the conclusion that we don't really have the skills and talents in our companies, because publishers and editors are accustomed to picking a manuscript and creating a design on a flat page. They don't really know the full potential of 3-D and digital [5]," he said.

I'd have to agree, but for a different reason. Maurice Line, British Librarian, best sums up these types of situations this way: "Unless we can see our future in a far broader context, we may not have a future. Our territory is being lost while we think we are defending it, because we are defending the form and not the substance, and the substance is changing [6]. This is not an unusual problem. McAfee/Brynjolfsson, in their recent book Machine Platform Crowd, describe it this way: "Why are technology progressions so obvious in retrospect and hard to see while unfolding? Because incumbents are so proficient and knowledgeable about the status quo they are unable to see. It's described as the "curse of knowledge" [7].

The result for the buyers/users? The cost of the products is far exceeding the value provided, i.e., the product has reached commodity status. So, we must ask ourselves: How do we change this?

At the University of Oklahoma Libraries, we aren't waiting for an answer, we're creating it. But here's the thing; we're all in this together, so we need your help. For that to happen, we all need to realize that to create new value we need to move from seeing the information as the source of value, to unleashing the full potential of the information via excellence in virtual tools and physical spaces. We can take care of the physical spaces, and in a moment, I'll show you how we're doing that. But we need you to help us on the virtual side of the equation, because we need you to open up the information containers so that we can all obtain the additional value. Now some of this is already happening. For instance, we see it happening via:

- Open Access initiatives

- Open Educational Resources initiatives

- Grant funders wanting open research data

- Governments wanting open research data

- Researcher's wanting greater impact

All of these things are resulting in large amounts of open data that can be utilized. This trend is going to continue, and, in fact, some recent projections are claiming that by 2040 all peer-reviewed publications will be open access. So, it's time to prepare! A question that usually quickly follows is where will we see all of these things - open-access, virtual/physical environments, access tools - come together? I'd like to submit to you, it'll be at the library.

Yes, the next question is often: Why use the library as a test lab? Because "Libraries lead [in] Higher Education change for the following reasons: 


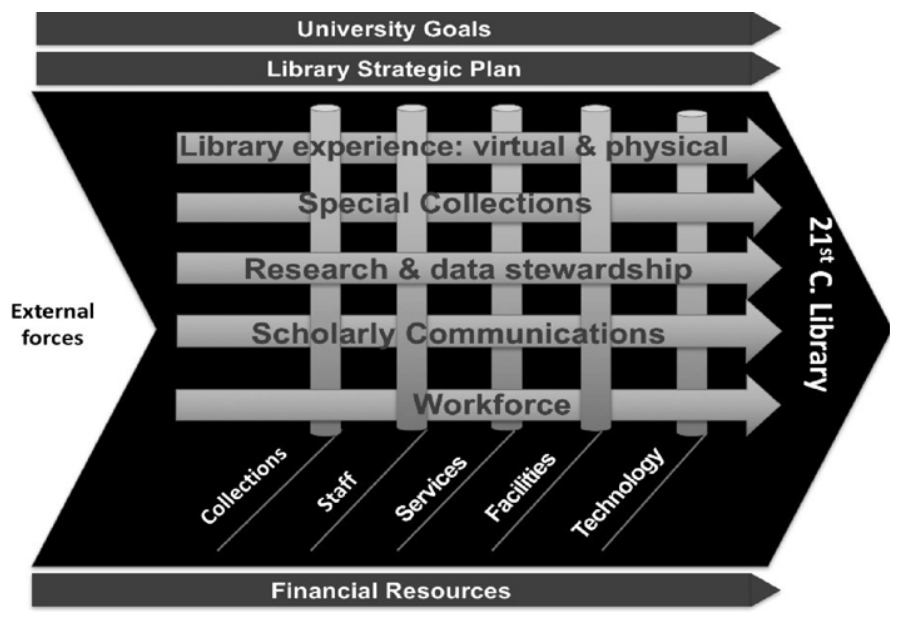

Fig. 1. University of Oklahoma Libraries, Strategic Plan Pillars.

- They are Experienced in Change Management

- From purchasing journals to licensing databases

- From housing books to providing collaborative work spaces

- Strong set of Campus Relationships

- Terrific position to catalyze change. Work with faculty, administrators, students and serve on campus committees.

- Physical Presence

- Heart of campus

- A place of gathering, solitude, connections and contemplation [8]."

Here are other reasons to consider:

- We have a large and rapidly growing repository of open texts (open access, OER's, HathiTrust, and more) to use.

- Plus, we have access to a LOT of licensed content.

- We're increasingly expressing knowledge in new formats.

- We're the intellectual crossroads. Ideas get refined and polished as a result.

- The library is the test-lab for the entire campus.

- The University of Oklahoma Libraries have a door count of over $1 \mathrm{M} / \mathrm{year}$.

- Some libraries are really very innovative and entrepreneurial!

Now, I'm not going to tell you that every library falls under the umbrella of all these descriptions, but those that do can be found. First, look for a strategic plan on their website, and if you find it, read it. For instance, ours at the University of Oklahoma Libraries (see Fig. 1) tells you we're focused on excellence in the library experience, both virtual and physical and on making our special collections a point of differentiation; that research, data stewardship and scholarly communications are key to our future, and so is our workforce. Those all represent places we're making strategic investments. 


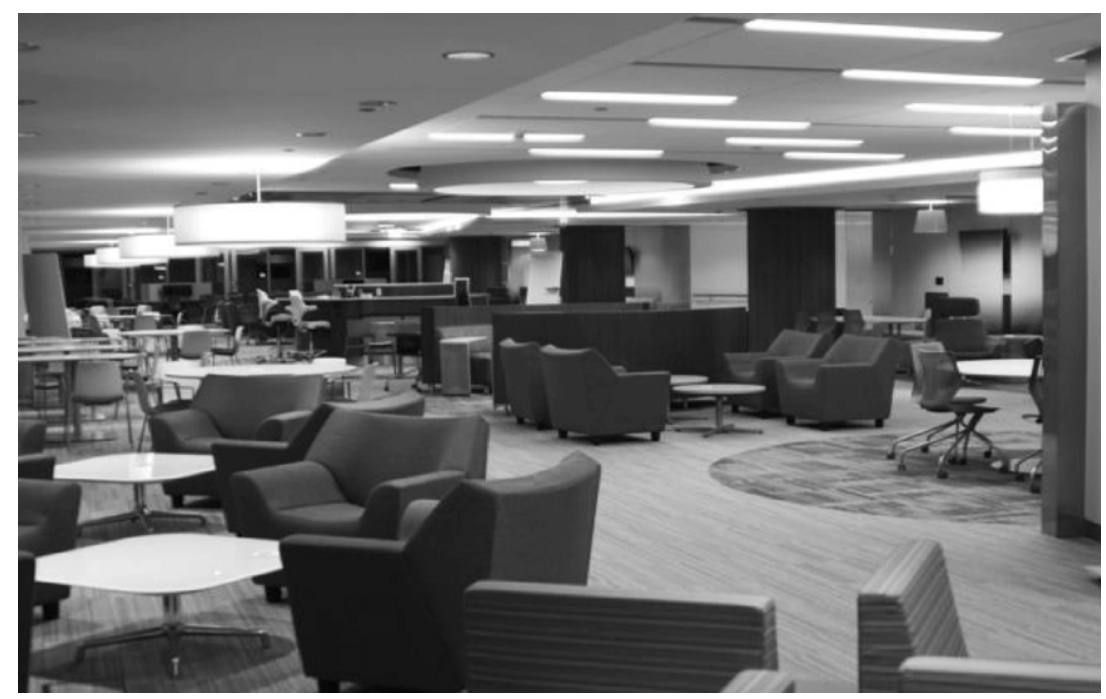

Fig. 2. University of Oklahoma Libraries, Helmerich Collaborative Learning Commons.

It's also important to remember that we've firmly positioned our libraries to be the "intellectual commons \& crossroads of the university." We see OU Libraries as a place where the scholarly output from knowledge domains of the various colleges on campus comes to interact with that from the other colleges; and, as I often tell people, it's a place not unlike a fast-flowing stream, where rough edges are smoothed to become polished pebbles. The library is a place where ideas can be bounced off of students/faculty/staff from other colleges, and then refined. We try to encourage that happening by building physical spaces that facilitate that kind of interaction. As such, we've built a large collaborative learning commons (see Fig. 2).

This space feature all types of seating, including furniture that is movable so it can be quickly reconfigured, spaces with technical support for projection and recording studios and flipped classroom support, and, of course, a coffee shop that sells snacks and drinks. Equally important to these spaces is that many of the all-too-common flat walls and ceilings have been redone into sweeping curves with multilayered and textured ceilings, with spaces that are open, and the few walls that are present reconfigurable. This conveys a sense of agility, flexibility, and accommodation. Walking down the main walkway on the day the new Helmerich Collaborative Learning Commons opened, I overheard one student turn to her friend and say: "We're not in Oklahoma anymore!" I think that conveys the attitude of many students towards this new space. The word we hear more often than not, after showing people this space, is "transformational."

However, that's only one of the physical spaces we transformed in pursuit of the goal of creating excellence. On the same floor, we wanted to test the concept that not only would undergraduate students want that kind of collaboration space, so would the faculty and graduate students. So, we also created a Digital Scholarship Lab (see Fig. 3) to bring a new definition to the word "value" when talking about what the Library provides in terms of digital scholarship for faculty and graduate students. As such, we equipped it with a state-of-the art video-conference room, including a privacy screen for conducting interviews. It also includes a small recording studio for faculty to use in preparing class lectures for 


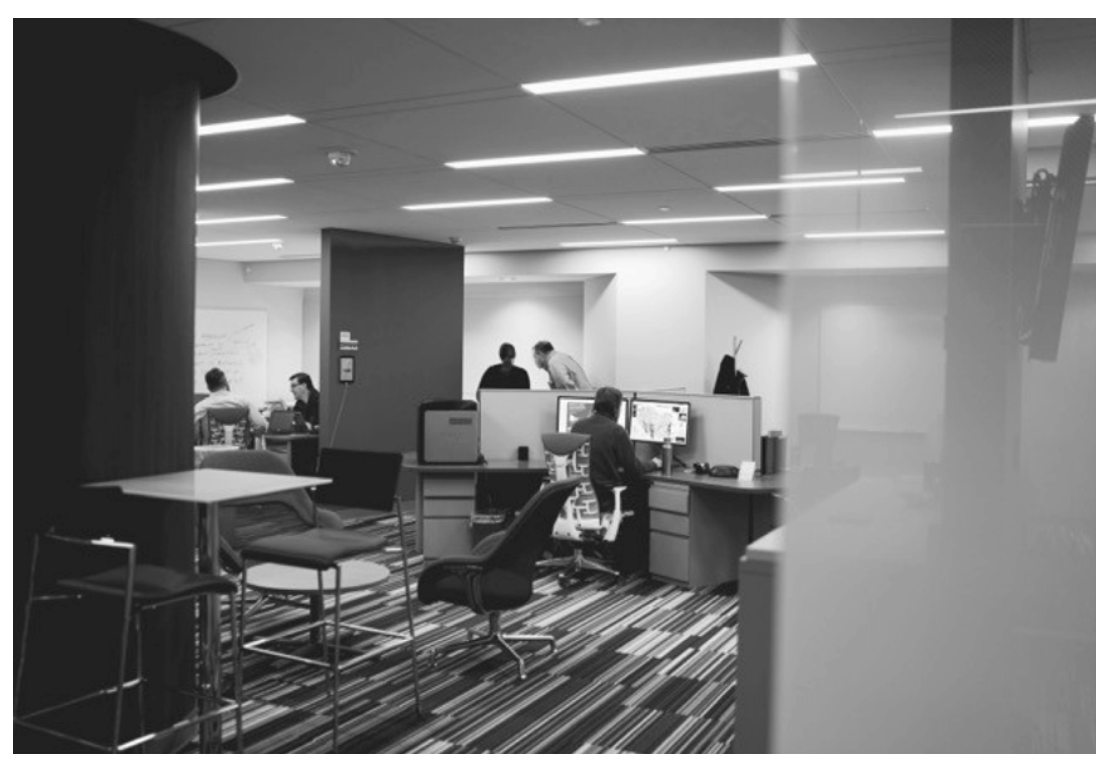

Fig. 3. University of Oklahoma Libraries, Digital Scholarship Laboratory.

"flipped" classes. There are also collaboration rooms which can be booked in advance, or used if open, for pulling together team members from across the campus in a central location, while surrounded by library resources and services to extend their research, learning, and pedagogy capabilities. Finally, we provided Digital Scholarship specialists to assist people to utilize this space to its fullest. As this area has gained traction it has become the loci for seminars held by the library, including Carpentries, Research Bazaars, and classes in 3D printing, virtual reality, and microcontrollers.

The Helmerich Collaborative Learning Commons (HCLC) is one of the most popular spots on campus, spawning requests for longer hours and more such space. We've responded with an extension called the "Learning Lab," (see Fig. 4) a space where we want to support undergraduate research and the skills associated with doing undergraduate research. Thus, we partnered with our Writing Center and Tutoring Center, to run a station in this area, staffed by people from the library, Writing Center, or Tutoring Center who are available to help students plan and conduct their research project. This space features all different types of seating, furniture and group and individual collaboration areas, as well as what are called "Brody's," (see Fig. 5) which students dub firstclassseating because they remind them of first class airplane seats. But no matter what you call them, if you're not in one by 8:30 in the morning, you'll not be likely to secure one for the day, due to their immense popularity.

At the same time that we were building the Learning Commons, our success with the students and the HCLC supported our belief that the same type of collaboration environment would greatly benefit our faculty and graduate students. So, we executed a plan to take another floor of the library and transform one wing into a faculty and graduate student center. This space was designed to have an aesthetic that would appeal to faculty, thus it features the use of more wood, bookcases with browsing shelves, and spaces with fireplaces and comfortable seating, as well as individual study rooms. Since the individual study spaces are segregated, we also built a large collaboration space called the "Scholar's Lounge," (see Fig. 6) which is designed to facilitate and encourage interaction, casual conversations, and idea exchange. We 


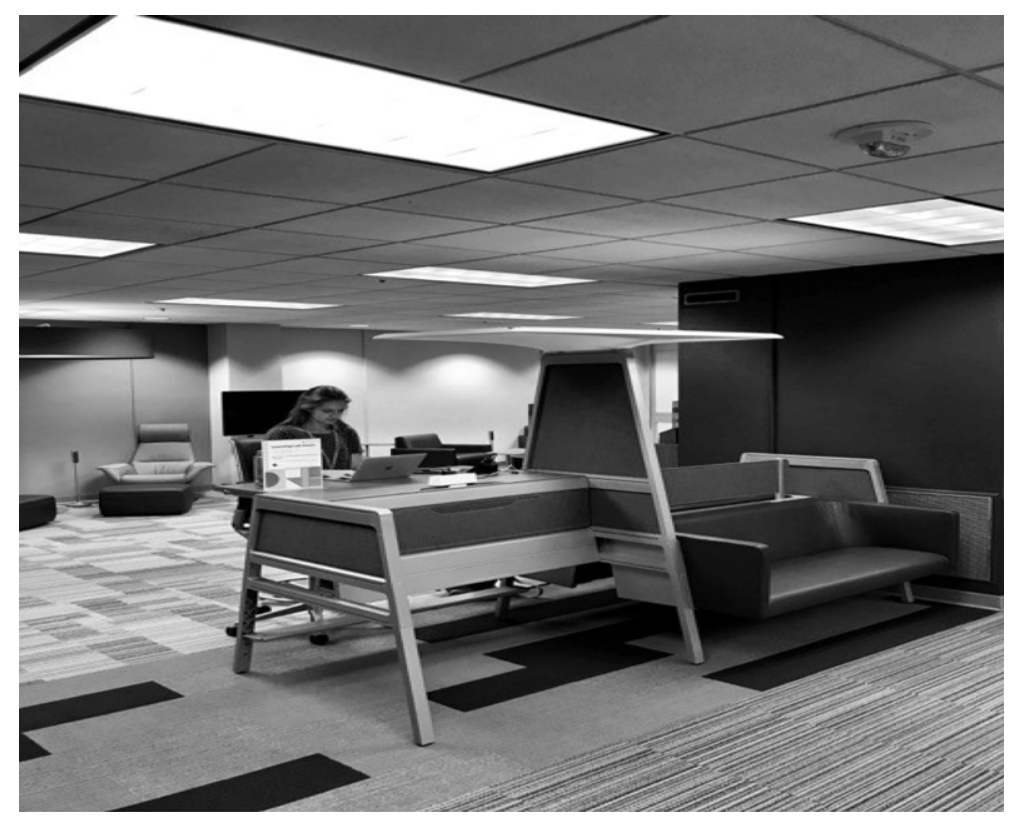

Fig. 4. University of Oklahoma Libraries, Learning Lab.

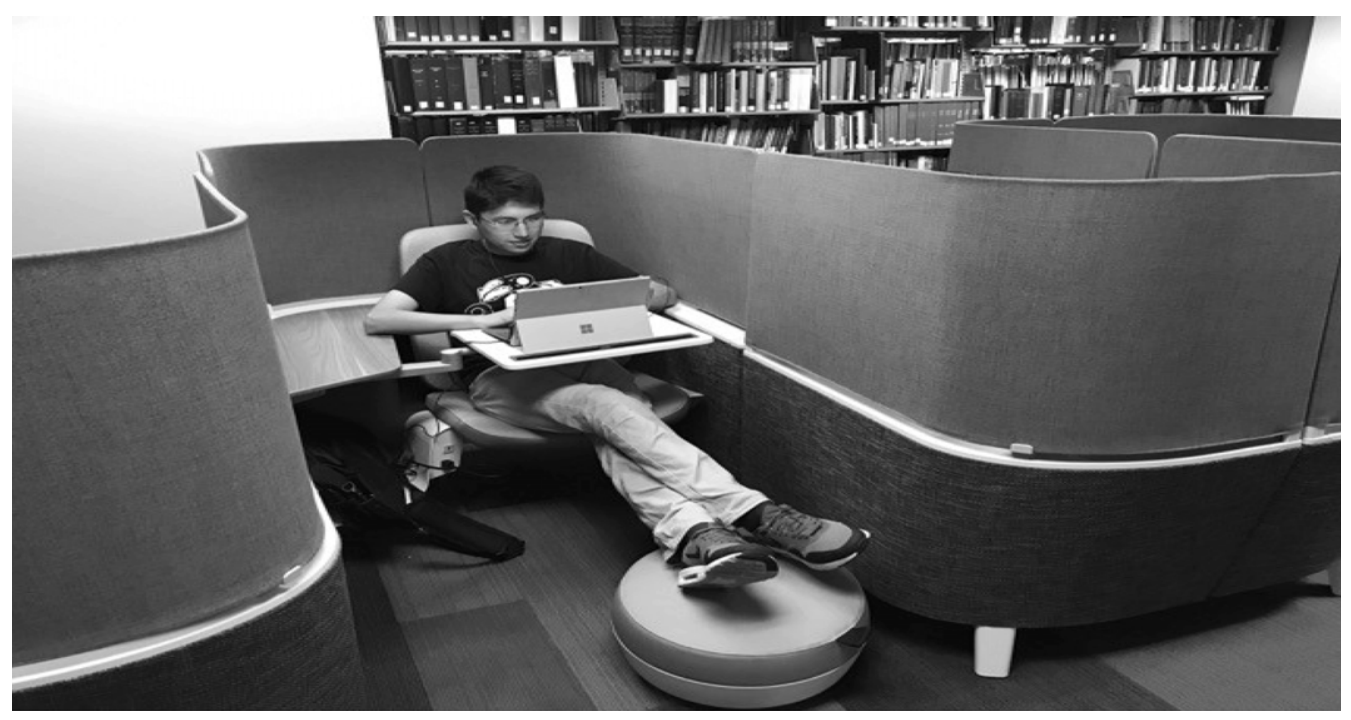

Fig. 5. University of Oklahoma Libraries, Learning Lab "Brody” Seating.

also created a Data Consortium space (see Fig. 7). This space is a shared initiative by the libraries and the colleges to address the reality that a significant portion of research in nearly all fields has an ever evolving quantitative and qualitative data dimension. New methods of analysis such as visualization, modeling, data-mining, text-mining, computer theming, and image-mining are required to make sense of complex data sets and to augment more traditional analysis. So, we are assembling a group of knowledge experts 


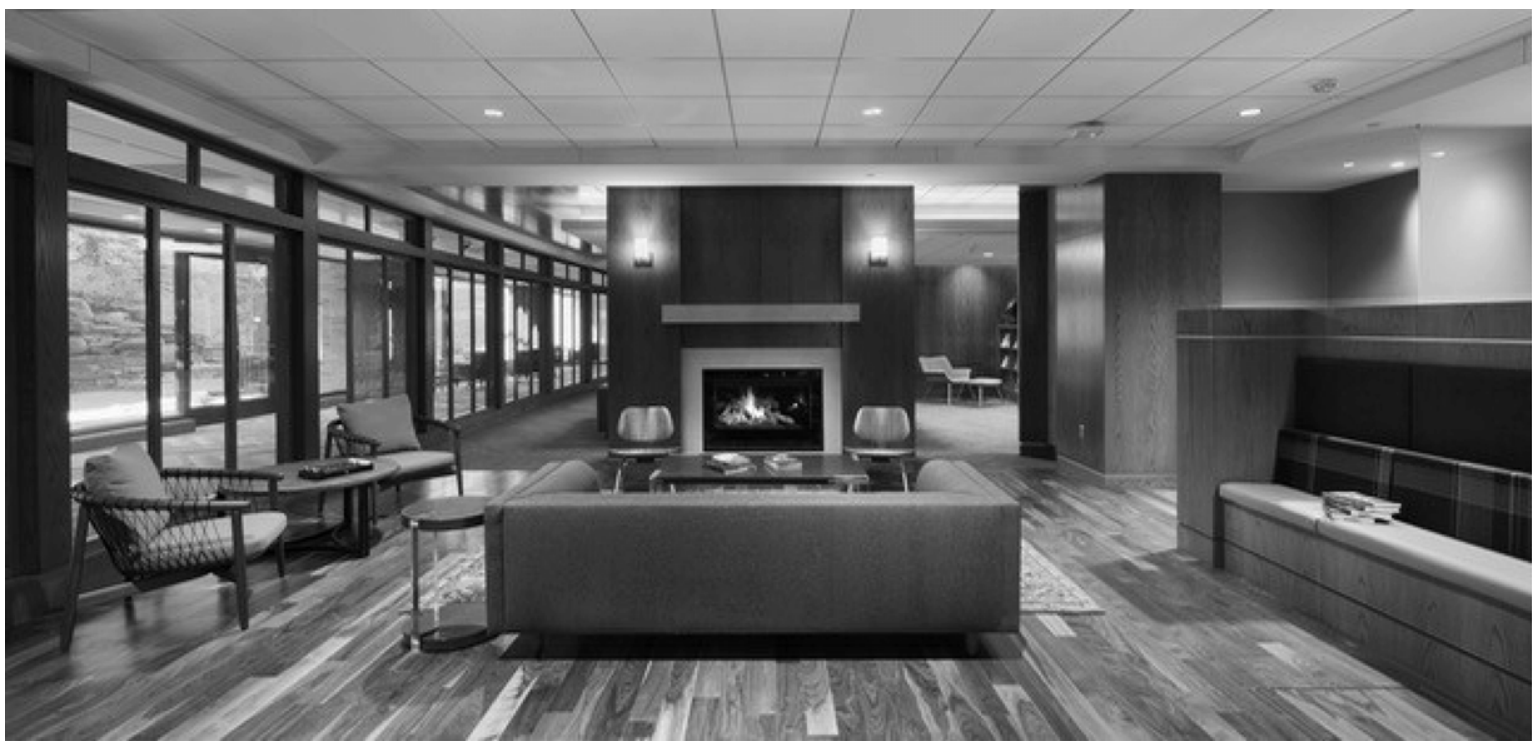

Fig. 6. University of Oklahoma Libraries, Scholar's Lounge.

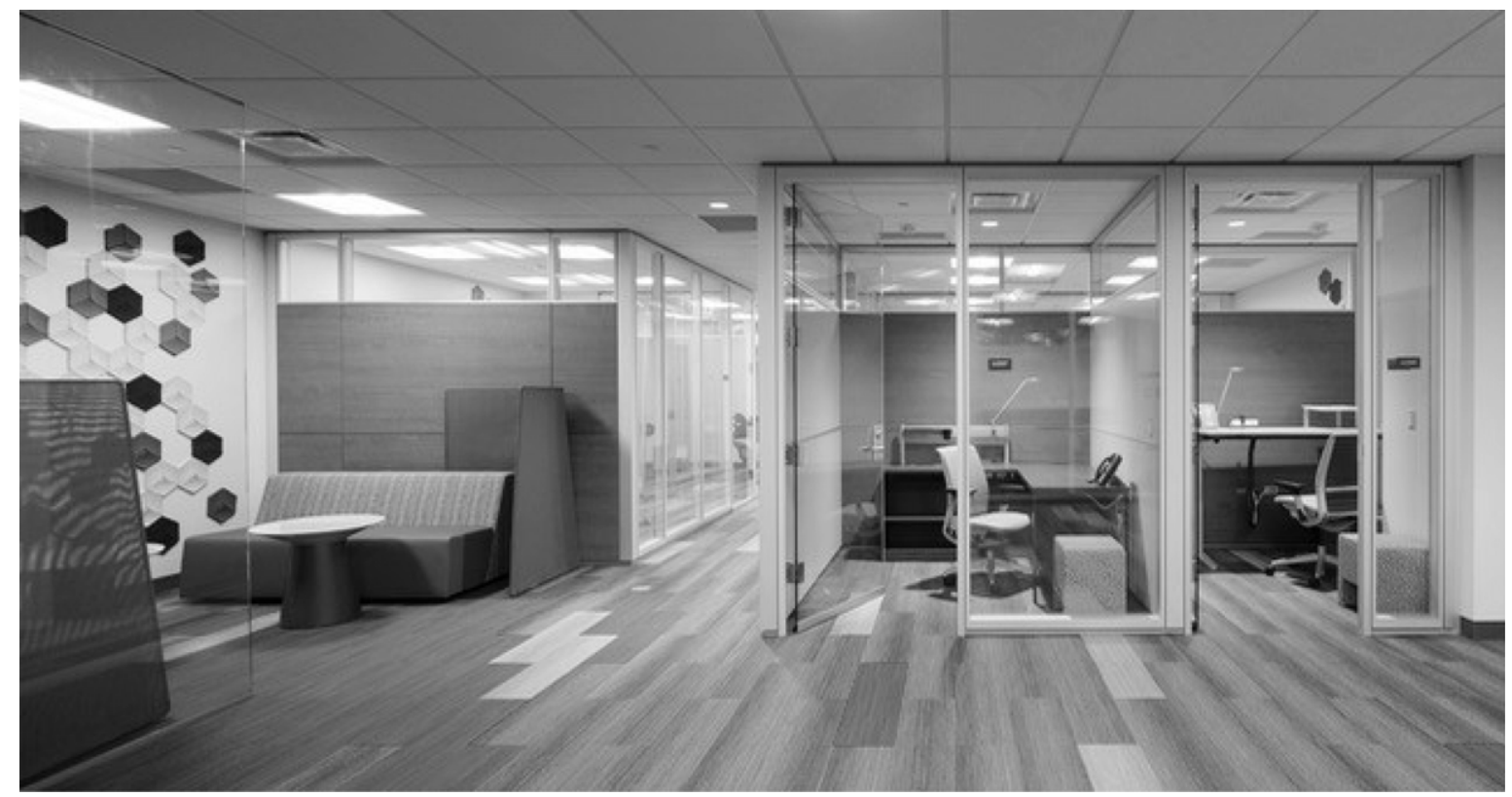

Fig. 7. University of Oklahoma Libraries, Data Analytics, Design and Evaluation Consortium Offices.

to provide research consultation and teach workshops. Through this space, we plan to offer access to specialized software packages and visualization environments; provide training and support in statistical, geospatial, and quantitative data analysis; and provide specified consulting expertise in the use of numeric, qualitative, and spatial data for research, including data access, analysis, collection, data management and reuse, citation, and preservation. 


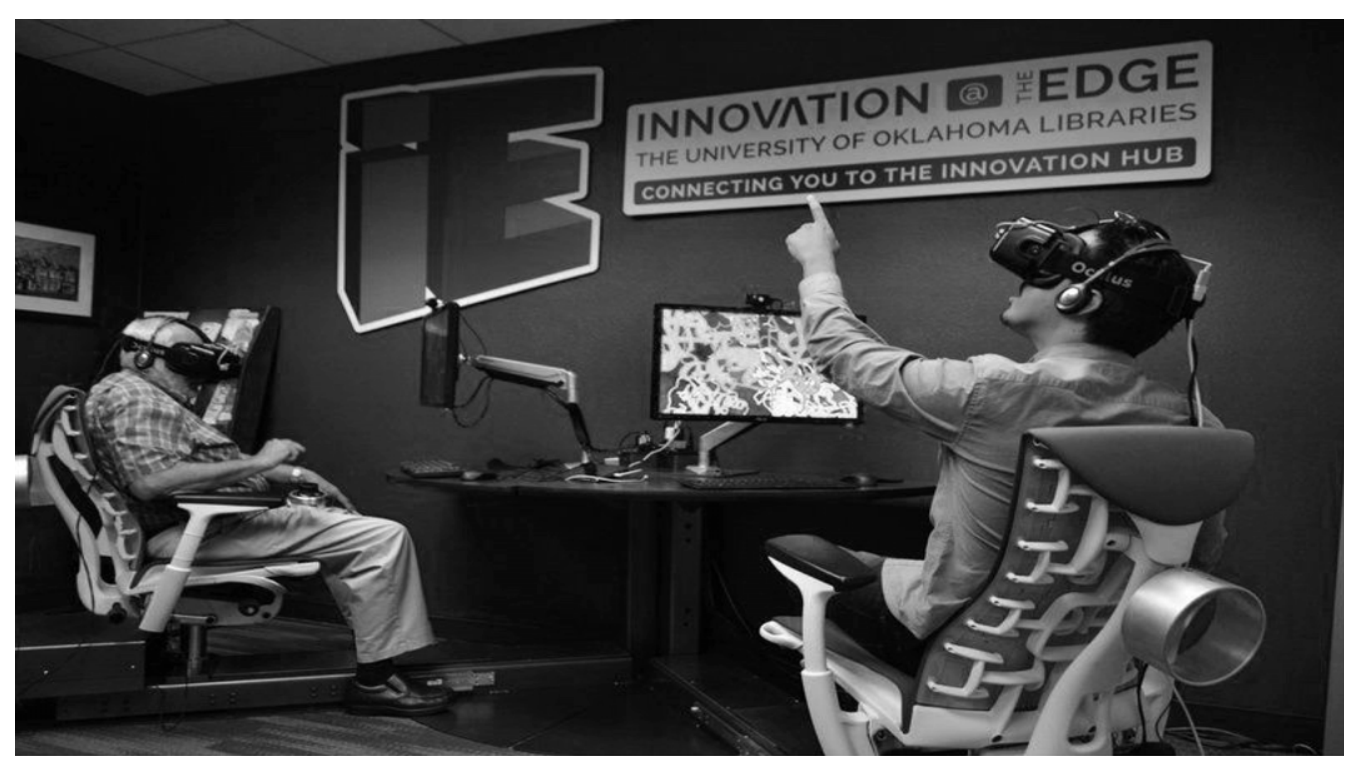

Fig. 8. University of Oklahoma Libraries, Innovation @ the Edge.

One of the libraries most successful spaces is the Innovation @ the Edge (see Fig. 8). A 250 sq. ft. space that is a combination of makerspace, Fablab, startup incubator, classroom, laboratory, and work space. Within that space, we strive to create a culture of experimentation and knowledge creation using the latest technology. This space facilitates the creation of collaboration and community around utilizing these technologies. Currently, it features virtual reality, 3D visualization/printing, microcontrollers, and courses in the Carpentries (software, data and more) as well as some early efforts at robotics and artificial intelligence adoption. The Innovation @ the Edge has earned the Oklahoma University Libraries two Campus Technology Futurist awards, a great deal of positive press coverage, and the attention of virtual reality equipment manufacturers, who have supported our efforts to increase the use of virtual reality in pedagogy and research through donations of equipment. Faculty willing to embrace the technology have also become ardent advocates for its further use and adoption.

Here is a comment from Professor Elizabeth Pober of the College of Architecture:

"Finally having some time to watch the videos and reflect... I am deeply moved. I have been trying to teach my students spatial skills for ten years now. I have gone from chalk and cardboard refrigerator boxes in the parking lot in my first trials to now working with you and using the OVAL platform. The impact on the students this week was immeasurable and the impact on me has been profound."

Another comment was from Professor Bill Endres, of the College of Arts and Sciences: "At the International Medieval Congress in Leeds, UK, people loved my 3D printed pages of the St. Chad Gospels. They were lauded as likely the world's first 3D printing of a manuscript page. However, my favorite comment was: "I have now touched the internet." (Bill has interactive 3D renderings on his website. See: http://bill.oucreate.com/.)

At Oklahoma University Libraries, we haven't just spun these technologies up as independent technologies, we're actively working to integrate them into the fabric of our university and our libraries. For instance, when someone searches our website, they will see, in the list of hits returned a button where, with one additional click, the subject they've searched will be searched in the major 3D aggregation sites 


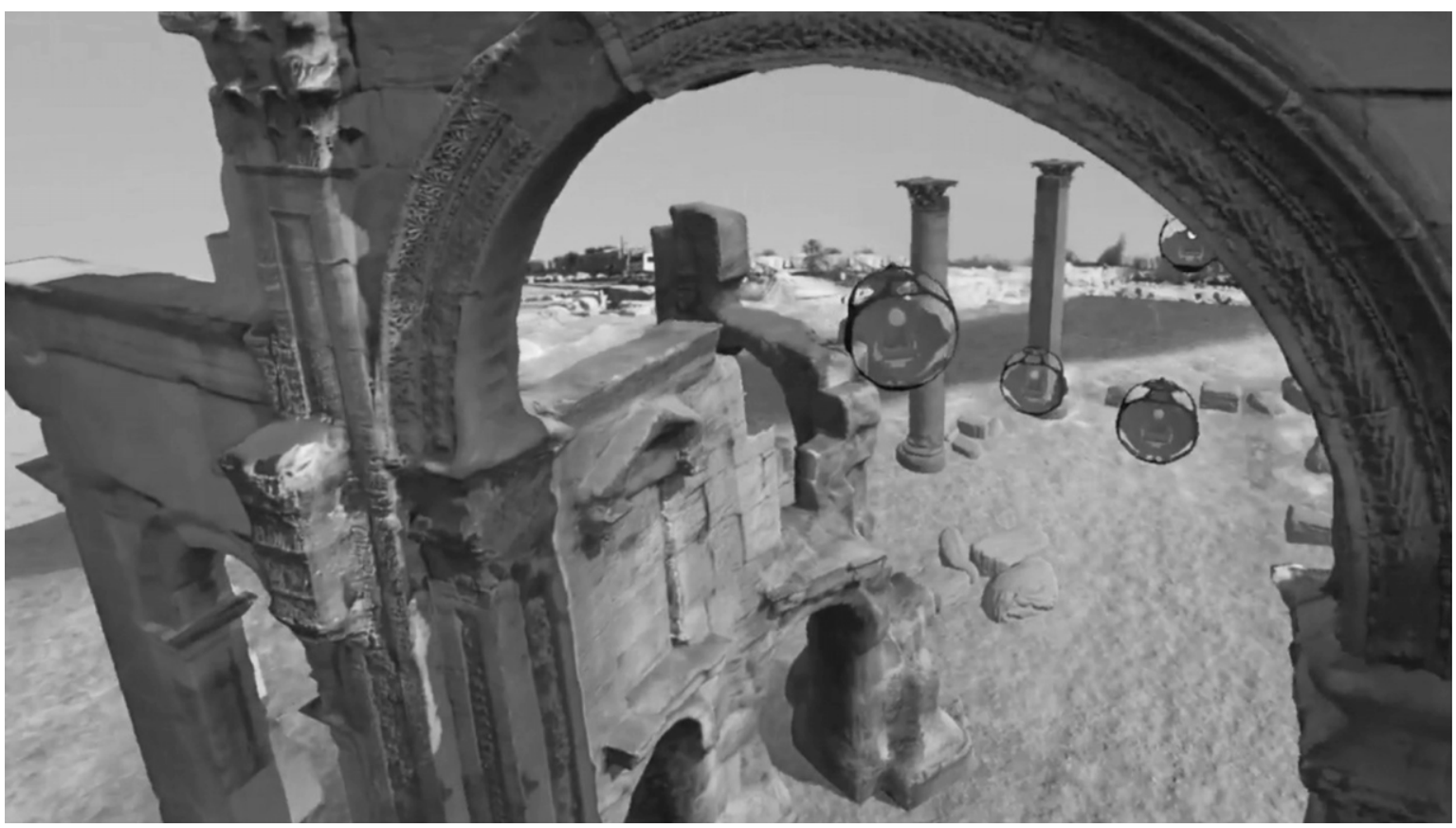

Fig. 9. University of Oklahoma Libraries, Innovation @ the Edge, Virtual Reality Class Screen Shot.

on the web. By selecting one of those objects, it can then be immediately downloaded and pushed to one of our virtual reality workstations or to a $3 \mathrm{D}$ printing queue, so that when the person arrives at the Innovation @ the Edge, it is ready for their use.

Recently, we've been using virtual reality to redefine what an instructional session is, and where it can be held. In September 2017, for the first time ever, a virtual reality class (see Fig. 9) was held in higher education across seven remote locations (two in Arizona, five in Oklahoma) with fifteen total participants, including an expert instructor in Arizona who gave a tour of a cave inaccessible to the public (but that we had been allowed to recreate in Virtual Reality for this purpose,) pointing out the archaic cave art and explaining it to the attendees. More such sessions are now being planned because they simply allow people to go into places that are otherwise inaccessible and yet, through the use of these technologies, to learn about those places.

We're also demonstrating inter-disciplinary collaboration by partnering with the private sector on a broad range of ideas. For instance, another area we're showing what the future might include is with books. Remember the comment we mentioned earlier by the CEO of a publishing company? Kevin Kelly, in his book The Inevitable that I mentioned earlier provides a great answer as to why what that CEO says about the future is so wrong: "The real magic will come as each word in each book is cross-linked, clustered, cited, extracted, indexed, analyzed, annotated, and woven deeper into the culture than ever before.... In the new world of e-books, every bit informs another, every page reads all the other pages." Kelly is right, and the technology to do these kinds of things is out there now. Our efforts are focused on bringing them together to show results. We've been working with an Oklahoma company called Exaptive to show exactly how what Kevin Kelly is describing can be done today. Early results are incredibly encouraging, and we 
see far more applications for this type of technology in the future. You'll read more about their approach in a following section.

We also have partnerships with firms like Next Thought, also out of Oklahoma, who demonstrate a deep understanding of networking and collaboration and how to use that understanding to build interactive learning communities. You'll also find more detail on this organization in the next section. Other collaborations, where we're either an active development partner or a testing partner, include collaborations with the Ex Libris Group to build a research output management system (now named Esploro), and also with Gale Research to build a Digital Scholarship tool.

All of what I've mentioned, however, needs all of us to work together to build information containers that are more open in order to unleash the additional value held by that information, and to allow for new value creation to happen on top of those open information resources and products. They are also massively dependent on collaborative environments, physical and virtual, in order to fuel the creation of that value. Which serves as an important transition point to examine the thinking of two of the partner firms I've just mentioned we work closely with in our efforts.

\section{Connected! Connections are EVERYWHERE - Use them!}

Ken Parker, CEO and Co-Founder of NextThought (https://nextthought.com/), co-presented with me at the 2018 Annual Conference of the National Federation of Advanced Information Services (NFAIS) in February (this paper is based upon my talk) and the following comments are based upon his discussion.

Ken noted that collaborations involve connections and connections create our reality at every level. To understand them better, he examined connections at three levels:

- Nature

- Human Activity, and

- Education in particular

He said that one need only to pause and think about where one sees connections in nature, although few of us do this on a regular basis. However, that's frequently because we see them in a disjointed context. If one examines pictures of the cosmic web and compares them with images of nerve cells in the human body, there exist remarkable similarities. The major difference between the two? Thirty-two orders of magnitude!

Parker said that we can look at nature and see single cell bacteria interlinking in highly-organized fashions. We can also clearly observe human kidneys reacting to signals from bacteria in our intestinal tracks and modifying blood pressure after meals. Our understanding of how symbiotic microbes affect health is becoming much more molecular.

At a human activity level, we're seeing economic, social, physical, and emotional changes that are attributable to connections. Studies from a recent book by Matthew Lieberman of UCLA, Social: Why Our Brains Are Wired to Connect [9], have shown that the human brain is optimized for and craves social connections. To fail to utilize those capabilities is to miss out on realizing human potential. We are designed to connect.

The book The Inevitable by Kevin Kelly, mentioned earlier, also provides insights here. In outlining some of the major trends Kelly sees occurring, those that apply to connections include: 
- Accessing and Exchanging. The idea that ownership is being replaced by access in order to support streaming, connecting, and aggregating.

- Platforms. The idea that connecting and exchanging allows communities to create new value that is not only more personalized, but also that is more data-driven. Uber, Airbnb, and Spotify are all examples of these trends.

- Sharing is also growing, as Kelly points out. Whether it's code, knowledge, judgment or photos, increasingly people are sharing what they produce. Fedora, Facebook, Flicker, and Instagram are all modern examples of these trends. Cooperation, collaboration, collectivism, and connections all support this sharing trend.

- Remixing, while a profoundly old concept, is being recharged by modern technologies such that it is now possible to radically deconstruct, find, recombine, and produce a transformed object. We're seeing this happen in products, tools, skills, and in educational courses.

So, with that context, let's turn back to education. Specifically, how do connections help education? Learning communities have always supported great education. Benjamin Bloom, in 1984, discovered that a powerful ingredient in successful education was the addition of tutors [10]. When tutors were added into learning, the average tutored student exceeded $98 \%$ of their peers.

Today, we're seeing efforts to connect students with alumni that prove promising. This process is called "Alumnification." In the end, if we can imagine educational processes that harness connections in learning communities as well as those resulting from alumnification and combines those with open access to the internet, the future of learning would seem to have unlimited potential.

\section{We don't need more social networks, we need more cognitive ones!}

Dave King, Founder and CEO of Exaptive, Inc. (https://www.exaptive.com/), also co-presented with me at the 2018 NFAIS Annual Conference and the following is based upon his comments. He discussed main principles and how at Exaptive they are applying those principles in a very tangible and real way to facilitate a large team of scientists searching for and creating new discoveries. Dave noted that making discoveries is requiring the efforts of more and more people. A 2017 Working Paper from the National Bureau of Economic Research (NBER) showed that while "in the 1950's a research paper typically only had one or two authors, by the 2000's, the effective number was twenty three." [11] Which means, as technologists, we can't just design tools for the individual scientist; we have to start thinking about tools for groups of scientists and for large-scale collaborations. We need to make "innovation engines" that aren't just powered by "big data", but are powered by big groups.

Civil engineers have been doing this for hundreds of years. They have created innovation machines all around the globe that take in large groups of people and produce new and novel ideas, and those innovation machines are called cities. Cities are where lots of people get squeezed together in very little space, and the network-effects that occur in these conditions lead to the vast majority of all the Intellectual Property produced in the world.

Similarly, cognitive cities use artifacts generated by researchers to make recommendations on collaborations. The important thing in a cognitive network is being able to make suggestions for innovations that aren't about maximizing similarity. The reality is that many people face similar challenges, but in entirely different jobs. Yet the solutions can often easily be transferred between areas. The question is: Can we use technology to build virtual cities that generate even more Intellectual Property than physical cities and that 
lead to even more discoveries? By using concept matching, we believe it is possible and we are using our software to prove that point. We can link people together around concepts and suggest teams that could benefit from working together. It becomes rather staggering to see the possible team configurations that can result containing overlaps to be explored and that can result in substantial discoveries.

Dave noted that Exaptive did this at the University of Oklahoma, where they worked with a professor in Arabic studies who wanted to find a concept in multiple languages and countries. They connected this person with another person through one of these cognitive networks. Remember, a cognitive network is like a social network because it involves people, but it's not about being social. It's about facilitating thought. The first step in joining the cognitive network is to get the ideas that are in the participants heads converted into some tangible form.

As Exaptive facilitated their discussion through their product, something subtle happened, and it's worth pointing out because it gets at one of the key challenges inherent in cross-disciplinary collaboration. It's the challenge of domain-specific language. When two thinkers from two different fields get together, they rarely speak the same language.

When this happened, Exaptive saw one researcher who never used the word "concept," but rather preferred to use the word "entity." But, when talking to the University of Oklahoma researcher, he actually used the word "concept" five times within thirty seconds. Based on the Exaptive software, which is all about concept mapping, he intuitively was able to finding a common language that the University of Oklahoma researcher could understand. And when our researcher responded, he was not only able to make the conceptual leap to the other term he was also able to explain it in the language of medical research that the other researcher understood. These researchers, using the Exaptive software, had found the commonality between themselves, and then pushed the conversation in an entirely new direction by introducing a different dimension and bringing in the bear in their latest projects. These moments are called "exaptations" and you'll find they are quite contagious (and also the reason for the name of Dave's company!).

\section{Conclusion}

The three integrated presentations given at the NFAIS conference have collectively tried to demonstrate why libraries are seeking, in fact driving, change on their campuses. Along with oppressive costs of information is the need to unleash new value from the information silos, which will ultimately facilitate usability of the already existing information silos. The barriers between that future and today were identified and where they are already being overcome, such as the University of Oklahoma Libraries. We looked at what might result when that happens and furthermore we noted that not all of the solutions are technology, some are solutions that can be found in the physical spaces in which knowledge is created from information. Collaboration and spaces that facilitate collaboration were shown. Also, new ways to identify locations that are likely to be test sites for new products/services/technology is a possible outcome that could be derived.

My co-speakers underscored why the work being done at the University of Oklahoma Libraries is so important. Ken Parker from NextThought showed how connections exist in highly similar forms, from the cellular level all the way to the universe levels, differing in size, but not core functions. He then focused on how connections affect humans and how integral they are to the human existence. Finally, he examined education and how connections can be leveraged in education and the clear benefits that will result. 
Finally, Dave King of Exaptive demonstrated the need for environments where cognitive networks can be created, through physical space and/or virtual technologies, in order to drive new discoveries. Using real examples from the work of the Exaptive team, he showed how technology can be used to create boundary markers in order to drive research productivity by reaching across disciplines, in a structured way that results in bringing researchers together in ways to facilitate the creation of cognitive networks. He then identified some case examples, showcasing the University of Oklahoma Libraries and other organizations finding common concepts, challenges and solutions even though they are working in very different disciplines of study.

\section{Acknowledgements}

I would like to acknowledge Dave King, Founder \& CEO, Exaptive, Inc., and Ken Parker, CEO/CoFounder, NextThought for their collaborative participation with me in a session at the 2018 NFAIS Annual Conference as well as for their thoughtful input and review of this paper.

\section{About the Author}

Carl Grant is the Dean (Interim) at the University of Oklahoma (OU) Libraries. His efforts in utilizing technology to underscore the library's positioning as the "intellectual crossroads of the university" have been a key part of the reshaping of an R1 research library and have included the Galileo's World exhibition, Innovation @ the Edge (featuring VR, 3D printing, Software Carpentry, Microcontrollers, etc.) a Digital Scholarship Lab and more. He has held senior executive positions in a number of library-automation companies. Carl has demonstrated his commitment to libraries, librarianship, and industry standards through participation in the CNI, ALA, ACRL, LITA, and on the board of the National Information Standards Organization (NISO). He holds a master's degree in library and information science from the University of Missouri at Columbia. Email: carl.grant@ou.edu.

\section{References}

[1] T.L. Friedman, Thank You for Being Late; An Optimist's Guide to Thriving in the Age of Accelerations. Farrar, Straus and Giroux, New York, 2016, p. 22.

[2] K. Kelly, The Inevitable; Understanding the 12 Technological Forces that will Shape our Future. Penguin Books, New York, 2016, Loc. 2441.

[3] Big Data: 20 Mind-Boggling Facts Everyone Must Read, Forbes, September, 30, 2015 (See: https:/www.forbes.com/sites/bernardmarr/2015/09/30/big-data-20-mind-boggling-facts-everyone-must$\mathrm{read} / \# 22 \mathrm{ab} 33 \mathrm{fd} 17 \mathrm{~b} 1)$, cited 11 June 2018.

[4] S. Sloman and P. Fernbach, The Knowledge Illusion; Why We Never Think Alone. Riverhead Books, New York, 2017 , p. 26.

[5] 'Ebooks are stupid', says head of one of world's biggest publishers, The Guardian, 20 February 2018 (https://www.theguardian.com/books/2018/feb/20/ebooks-are-stupid-hachette-livre-arnaud-nourry), cited 10 June 2018.

[6] M. Line, Librarianship as it is practiced: a failure of intellect, imagination and initiative, in: Interlending \& Document Supply, Vol. 33, Emerald Group Publishing, 2005, ISSN 0264-1615, p. 112.

[7] A. McAfee and E. Brynjolfsson, Machine Platform Crowd; Harnessing our Digital Future. W.W. Norton \& Company, New York, 2017, p. 21.

[8] J. Kim, Why the academic library should lead higher ed change, Inside Higher Education (12 March 2014). 
[9] M. Lieberman, Social: Why Our Brains Are Wired to Connect Oxford University Press, October 2013, ISBN: 9780199645046.

[10] M. Nebra, Solving the education conundrom of our time: Bloom's 2 Sigma problem, Class Central (20 March 2016) https://www.class-central.com/report/blooms-2-sigma-problem/ (last accessed 16 June 2018).

[11] N. Bloom, C.I. Jones, J. Van Reeneen and M. Webb, , , Are Ideas Getting Harder to Find (September 2017), National Bureau of Economic Research Working Paper No. w 23782. Available at SSRN: https://ssrn.com/abstract=3035132. 